ISSN: $1410-8917$

Jurnal Kimia

Sains \&

Aplikasi
Jurnal Kimia Sains dan Aplikasi Journal of Scientific and Applied Chemistry

Journal homepage: http://ejournal.undip.ac.id/index.php/ksa

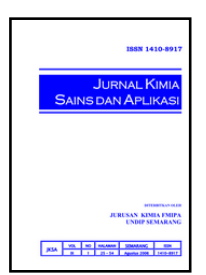

\title{
Isolasi, Identifikasi serta Uji Aktivitas Sitotoksik Senyawa Alkaloid Total Daun Ketapang (Terminalia Catappa Linn.) dengan Metode Brine Shrimp Lethality Test (BSLT)
}

\author{
Choirulina Maulida ${ }^{a}$, Dewi Kusrini ${ }^{a^{*}}$, Enny Fachriyah ${ }^{a}$ \\ a Organic Chemistry Laboratory, Chemistry Department, Faculty of Sciences and Mathematics, Diponegoro University, Jalan Prof. \\ Soedarto, Tembalang, Semarang \\ * Corresponding author: dewi.kusrini@live.undip.ac.id
}

\section{Article Info}

Keywords:

Terminalia catappa

Lin., alkaloid,

activity test, BSLT

\section{Abstract}

Isolation of alkaloid compounds on the leaves of T. catappa which is a combretaceae family plant has been performed. Isolation of alkaloids was performed by maceration method using $\mathrm{n}$-hexane solvent followed by ethanol. Ethanol extract was identified using dragendorf and meyer reagents, followed by hydrolysis of ethanol extract. Liquid-liquid extraction was then performed using an ethyl acetate solvent and produced a total alkaloid isolate. Alkaloid isolate analysis was performed by TLC method and separation with preparative TLC. Then, followed by analysis using UV-Vis, FTIR and LC-MS and cytotoxic test by BSLT method. The alkaloid isolates from the leaves of T. catappa were white powders. UV-Vis spectrophotometer analysis showed that isolates A1.1 and A2.1 had $\lambda_{\max }$ of $220 \mathrm{~nm}$. While the FTIR spectra showed that each isolate had a wave number of $3441.01 ; 3425,58 \mathrm{~cm}^{-1}$ (vibration $\mathrm{OH}$ ), 2924,09 and 2854,65 $\mathrm{cm}^{-}$ ${ }^{1}$ (vibration stretches $\mathrm{CH}$ asymmetry and symmetry), $1627.92 \mathrm{~cm}^{-1}$ (vibration $\mathrm{C}=0$ ), 1103.28 $\mathrm{cm}^{-1}$ (vibration of $\mathrm{CO}$ stretched symmetry with vibration $\mathrm{CN}$ ). LC-MS results showed compounds having molecular weight of $337.34 \mathrm{~g} / \mathrm{mol}$ (A1.1) and $337.33 \mathrm{~g} / \mathrm{mol}$ (A2.1). The compound was thought to be a tropane alkaloid compound with a group of $\alpha, \beta$ unsaturated acids and its isomers. The cytotoxic test using BSLT method showed that total alkaloid had $\mathrm{LC}_{50}$ value $132.59 \mathrm{ppm}$ that meant total alkaloid was not toxic.

\section{Abstrak}

Isolasi senyawa alkaloid pada daun T. catappa yang merupakan tumbuhan famili combretaceae telah dilakukan. Isolasi alkaloid dilakukan dengan metode maserasi menggunakan pelarut nheksana dilanjutkan dengan etanol. Ekstrak etanol diidentifikasi menggunakan pereaksi dragendorf dan meyer, diikuti dengan hidrolisis ekstrak etanol. Kemudian dilakukan ekstraksi cair-cair menggunakan pelarut etil asetat dan menghasilkan isolat alkaloid total. Analisis isolat alkaloid dilakukan dengan metode KLT dan pemisahan dengan KLT preparatif. Lalu, dilanjutkan dengan analisis menggunakan UV-Vis, FTIR dan LC-MS serta uji sitotoksik dengan metode BSLT. Isolat alkaloid dari daun T. catappa berupa serbuk berwarna putih. Analisis spektrofotometer UV-Vis menunjukkan bahwa isolat A1.1 dan A2.1 mempunyai $\lambda$ max sebesar $220 \mathrm{~nm}$. Sedangkan spektra FTIR menunjukkan bahwa masing-masing isolat memiliki bilangan gelombang 3441,01; 3425,58 $\mathrm{cm}^{-1}$ (vibrasi ulur O-H), 2924,09 dan 2854,65 $\mathrm{cm}^{-1}$ (vibrasi ulur $\mathrm{C}-\mathrm{H}$ asimetri dan simetri), $1627,92 \mathrm{~cm}^{-1}$ (vibrasi ulur $\mathrm{C}=0$ ), $1103,28 \mathrm{~cm}^{-1}$ (vibrasi ulur C-O yang simetri dengan vibrasi ulur C-N). Hasil LC-MS menunjukkan senyawa mempunyai berat molekul sebesar 337,34 g/mol (A1.1) dan 337,33 g/mol (A2.1). Senyawa tersebut diduga merupakan senyawa alkaloid tropane dengan gugus $\alpha, \beta$ asam tak jenuh dan isomernya. Uji sitotoksik menggunakan metode BSLT menunjukkan bahwa alkaloid total mempunyai harga $\mathrm{LC}_{50}$ sebesar 132,590 ppm yang berarti alkaloid total bersifat tidak toksik. 


\section{Pendahuluan}

Ketapang (Terminalia cattapa) merupakan salah satu tumbuhan dari famili combretaceae yang banyak digunakan sebagai obat oleh masyarakat Indonesia. Secara tradisional daun ketapang digunakan untuk mengobati penyakit kulit, liver, pernafasan, perut, gonorrhea dan insomnia [1]. Ekstrak daun dan buah daunketapang memiliki aktivitas anti kanker, anti HIV, anti diabetes, memberikan efek anti oksidan serta memiliki aktivitas sebagai anti mikroba [2].

Kandungan kimia daun ketapang telah banyak diketahui antara lain senyawa fitol, asam palmitat, 1nonadekena [3], flavonoid, alkaloid, kaemferol, $\beta$ carotene, tanin, oktadekana dan saponin [4-6].

Alkaloid merupakan salah satu metabolit sekunder yang telah banyak diketahui aktivitasnya sebagai obat, seperti obat analgetik, obat untuk penyakit radang (inflamasi) serta mempunyai aktivitas sebagai anti tumor dan anti bakteri dan anti biotik serta anti malaria [7].

Akan tetapi jenis alkaloid dalam daun ketapang belum pernah dilaporkan sebelumnya maka menarik untuk diselidiki jenis alkaloid dalam daun ketapang.

\section{Metode Penelitian}

\section{Alat dan Bahan}

Peralatan gelas standar, pipa kapiler, chamber, spektrometer LC-MS, spektrofotometer UV-Vis (Shimadzu UV-1601), spektrofotometer IR (Shimadzu Prestige-21), lampu detektor UV (Spectroline ENF24/F), neraca analitik (Kern-870), vakum rotary evaporator (Buchi-B480. Daun ketapang, etanol, nheksan, etil asetat, $\mathrm{HCl}$ p.a, $\mathrm{NH}_{4} \mathrm{OH}$ p.a, plat KLT silika gel $\left(\begin{array}{ll}60 & \mathrm{~F}_{254}\end{array}\right), \mathrm{H}_{2} \mathrm{SO}_{4}$ p.a, pereaksi Meyer, pereaksi Dragendroff, kloroform p.a, benzena p.a, etil asetat p.a, aquades, garam krosok, larva udang.

\section{Penyiapan Sampel}

Sampel penelitian (daun ketapang) dibersihkan, dikeringkan dengan cara diangin-anginkan dan dihaluskan sehingga diperoleh serbuk daun ketapang.

\section{Pembuatan Ekstrak Etanol}

Sebanyak 500 gram simplisia dimaserasi dengan nheksan sampai bening. Filtrat dipisahkan dan residunya dikeringkan kemudian dimaserasi kembali menggunakan etanol hingga bening. Selanjutnya filtrat diuapkan menggunakan rotary evaporator sehingga diperoleh ekstrak kental etanol.

\section{Uji Golongan Alkaloid}

Simplisia dan ekstrak etanol daun ketapang diuji golongan alkaloidnya menggunakan pereaksi Dragendorf dan Meyer. Uji golongan alkaloid dilakukan sesuai dengan metode yang telah dikemukakan oleh [8].

\section{Isolasi Alkaloid Total}

Ekstrak etanol yang telah didapatkan, ditambahkan larutan $\mathrm{HCl}$ hingga $\mathrm{pH} 3$ kemudian diekstraksi menggunakan etil asetat. Hasil ekstraksi akan terbentuk 2 lapisan, yaitu lapisan asam dan lapisan etil asetat. Kedua lapisan dipisahkan. Selanjutnya lapisan asam ditambahkan $\mathrm{NH}_{4} \mathrm{OH}$ hingga $\mathrm{pH} 9$ kemudian diekstraksi kembali menggunakan etil asetat. Hasil ekstraksi akan terbentuk 2 lapisan yaitu lapisan basa dan lapisan etil asetat, kemudian dipisahkan. Lapisan etil asetat dipekatkan menggunakan rotary evaporator hingga mengental (alkaloid total).

\section{Pemisahan dengan KLT}

Terhadap alkaloid total yang diperoleh dilakukan KLT dengan pengembang benzene:kloroform (4:1) menggunakan plat silika gel $60 \mathrm{GF}_{254}$ sehingga diperoleh noda-noda isolat. Selanjutnya dilakukan pemisahan menggunakan KLT preparatif.

\section{Karakterisasi Alkaloid}

Isolat alkaloid dianalisis melalui spektroskopi menggunakan spektrofotometer UV-Vis dan FTIR serta spektrometer LC-MS.

\section{Uji Sitotoksik}

Telur Artemia salina, Leach ditetaskan selama 2 hari di dalam air laut buatan yang dibuat dari 38 gram garam krosok yang dilarutkan pada $1000 \mathrm{~mL}$ akuades. Setelah larva berusia 2 hari, kemudian dimasukkan ke dalam larutan uji dengan konsentrasi 1000, 100 dan 10 ppm, setelah 24 jam dilakukan penghitungan larva yang mati. Uji sitotoksik dilakukan 3 kali percobaan untuk setiap ekstrak dan sebagai kontrol berupa air garam dan tween. Untuk menentukan harga $\mathrm{LC}_{50}$ digunakan analisis Probit melalui hubungan konsentrasi dengan persen kematian.

\section{Hasil Dan Pembahasan}

Ekstrak etanol yang dihasilkan berwarna coklat sebanyak 17 gram. Hasil uji golongan dengan pereaksi Dragendorf dan Meyer dkk. [9] menunjukkan bahwa ekstrak etanol mengandung alkaloid.

Ekstrak etanol dihidrolisis dengan $\mathrm{HCl} 2 \mathrm{M}$ hingga pH 3. Reaksi antara alkaloid dengan asam adalah [10]:

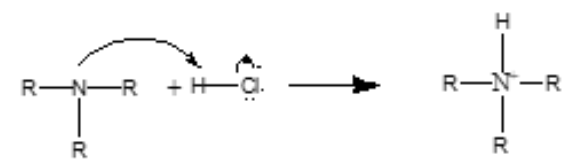

Hasil reaksi akan membentuk garam alkaloid, sehingga ketika diekstraksi menggunakan etil asetat senyawa alkaloid tidak larut dalam fraksi etil asetat. Lapisan asam kemudian ditambahkan basa sampai $\mathrm{pH}$ 9, sehingga terbentuk basa alkaloid kembali. Berikut merupakan reaksi antara alkaloid dengan basa [10]:

$$
\left.\right|_{R} ^{R} \longrightarrow \mathrm{NH}-\mathrm{R} \quad \mathrm{Cl}+\mathrm{NH}_{4}+\left.\mathrm{OH} \longrightarrow \mathrm{R} \longrightarrow\right|_{\mathrm{R}} ^{\mathrm{N}} \longrightarrow \mathrm{R}+\mathrm{H}_{2} \mathrm{O}+\mathrm{Cl}
$$

Alkaloid bebas ketika diekstraksi menggunakan etil asetat akan larut. Lapisan etil asetat diuapkan sehingga diperoleh alkaloid total, selanjutnya dilakukan identifikasi menggunakan KLT. Hasil KLT isolat alkaloid total ditampilkan pada gambar 1. 


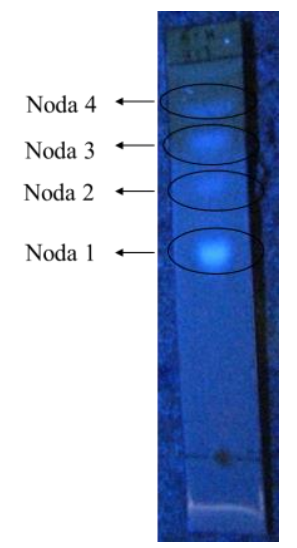

Gambar 1. KLT alkaloid total dengan pengembang kloroform:benzen (4:1)

Hasil KLT terlihat adanya 4 noda. Noda 1 mempunyai warna yang paling dominan, sehingga dilakukan pemisahan menggunakan KLT preparatif dengan pengembang kloroform:benzen (4:1). Hasil isolat KLT preparatif dilakukan KLT kembali menggunakan pengembang kloroform:benzen (5:1) dan menghasilkan 2 noda yaitu noda $\mathrm{A}_{1}$ dan $\mathrm{A}_{2}$, terhadap kedua noda kemudian dilakukan KLT kembali yang ditampilkan ditampilkan pada gambar 2 .

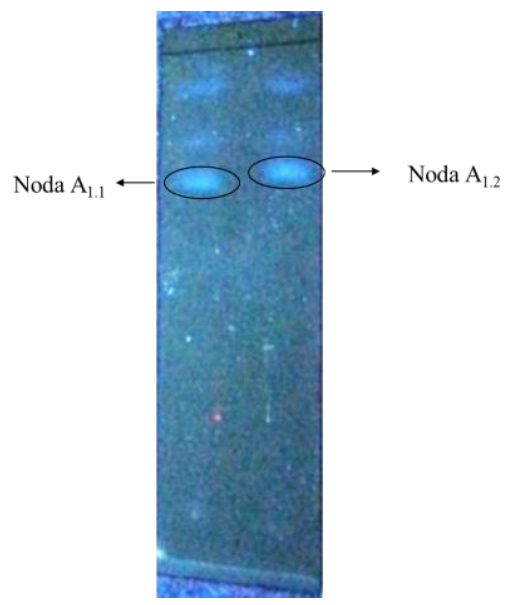

Gambar 2. KLT noda $A_{1}$ dan $A_{2}$

Hasil KLT menunjukkan Noda $\mathrm{A}_{1}$ dan $\mathrm{A}_{2}$ mempunyai 3 noda yang sama. Noda $A_{1.1}$ dan $A_{2.1}$ mempunyai warna yang lebih dominan, sehingga dilakukan KLT preparatif dengan pengembang kloroform:benzen (5:3) dan dianalisis menggunakan spektrofotometer UV-Vis dan FTIR serta spektrometer LC-MS.

Analisis isolat alkaloid menggunakan spektrofotometer UV-Vis dari kedua isolat (isolat $\mathrm{A}_{1.1}$ dan $\mathrm{A}_{2.1}$ ) ditampilkan pada gambar 3.

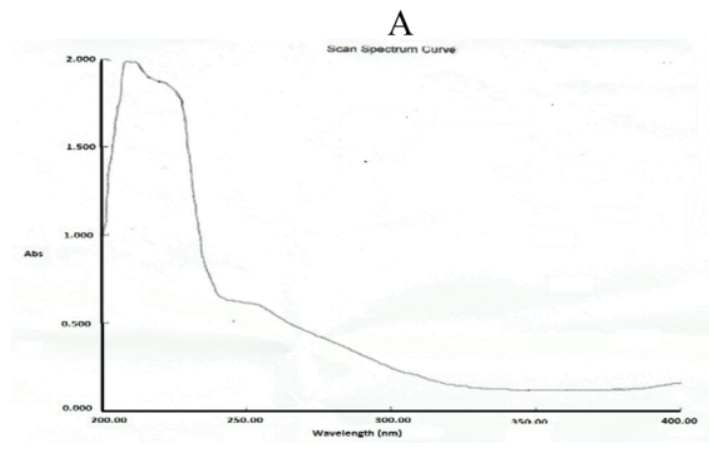

B

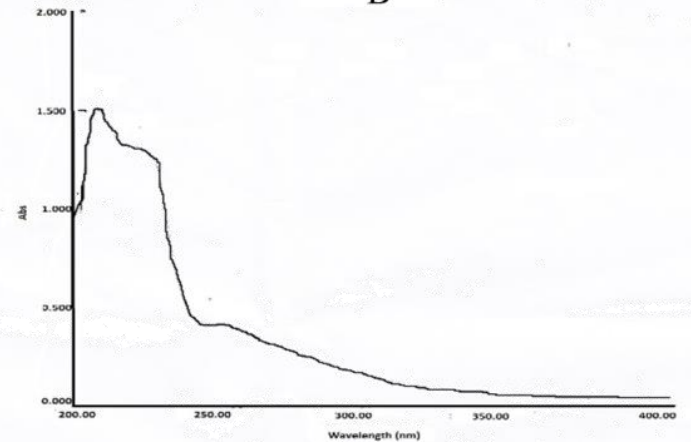

Gambar 3. Spektogram UV-Vis isolat $A_{1.1}(A)$ dan $A_{2.1}$ (B)

Hasil analisis spektrofotometer UV-Vis menunjukkan, kedua isolat alkaloid mempunyai $\lambda_{\max }$ sebesar $220 \mathrm{~nm}$ dan bahu $260 \mathrm{~nm}\left(\mathrm{~A}_{1.1}\right)$ serta $262 \mathrm{~nm}$ $\left(\mathrm{A}_{2.1}\right)$. Menurut Humam $d k k$. [11], $\lambda_{\max } 220 \mathrm{~nm}$ merupakan $\lambda_{\max }$ dari senyawa alkaloid tropan yang mengikat gugus $\alpha, \beta$ asam tak jenuh.

Analisis menggunakan spektrofotometer FTIR dari kedua isolat disajikan pada gambar 4 .

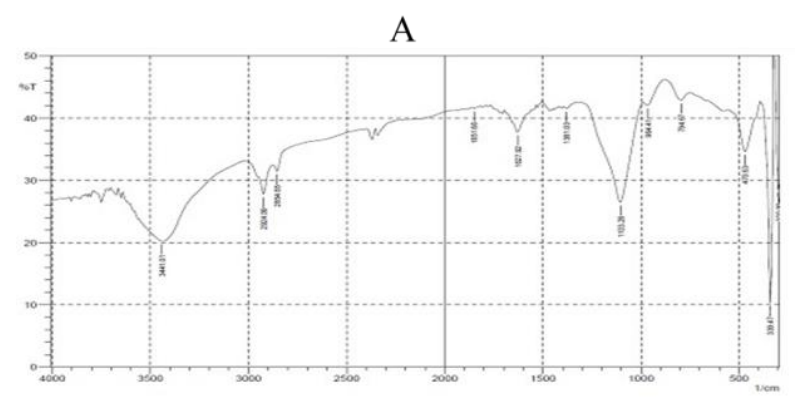

B

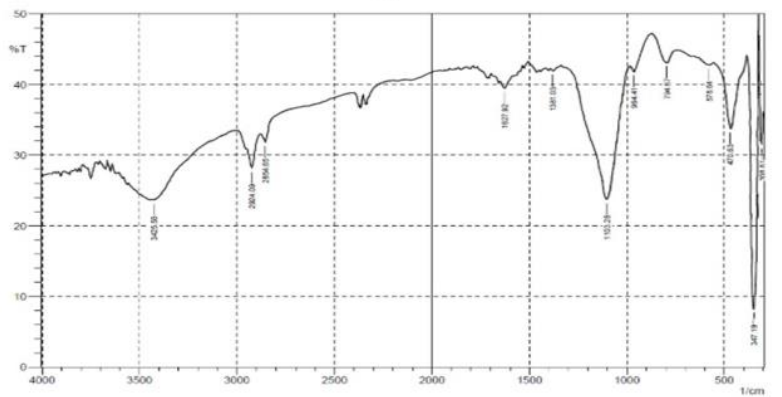

Gambar 4. Spektogram FTIR isolat $A_{1.1}(A)$ dan $A_{2.1}$ (B)

Hasil spektogram isolat alkaloid $A_{1.1}$ dan $A_{2.1}$ menunjukkan gugus-gugus fungsi dari senyawa yang ditampilkan pada tabel 1. 
Tabel 1: Data interpretasi spektogram FTIR isolat $A_{1.1}$ dan $\mathrm{A}_{2.1}$

\begin{tabular}{|c|c|}
\hline $\begin{array}{l}\text { Bilangan Gelombang } \\
\qquad\left(\mathrm{cm}^{-1}\right)\end{array}$ & Jenis vibrasi \\
\hline 3441,01 dan 3425.68 & Vibrasi ulur $\mathrm{O}-\mathrm{H}$ \\
\hline 2924,09 & $\begin{array}{l}\text { Vibrasi ulur -C-H } \\
\text { asimetri }\end{array}$ \\
\hline 2854,65 & $\begin{array}{l}\text { Vibrasi ulur }-\mathrm{C}-\mathrm{H} \\
\text { simetri }\end{array}$ \\
\hline 1627,92 & Vibrasi ulur $\mathrm{C}=\mathrm{O}$ \\
\hline 1381,03 & $\begin{array}{l}\text { Vibrasi ulur }-\mathrm{C}-\mathrm{H} \\
\text { alifatik bending }\end{array}$ \\
\hline 1103,28 & $\begin{array}{c}\text { Vibrasi ulur C-N yang } \\
\text { simetri dengan vibrasi } \\
\text { ulur C-O alkohol }\end{array}$ \\
\hline 794,67 & $\begin{array}{c}\text { Vibrasi ulur -C-H keluar } \\
\text { bidang }\end{array}$ \\
\hline
\end{tabular}

Hasil LC-MS menunjukkan bahwa isolat $A_{1.1}$ mengndung senyawa dengan berat molekul sebesar $338,34 \mathrm{~g} / \mathrm{mol}[\mathrm{M}+\mathrm{H}]^{+}$dan $360,28 \mathrm{~g} / \mathrm{mol}[\mathrm{M}+\mathrm{Na}]^{+}$. Isolat $\mathrm{A}_{2.1}$ mempunyai bobot molekul 338,33 $\mathrm{g} / \mathrm{mol}\left[\mathrm{M}+\mathrm{H}^{+}\right]$ dan $360,28 \mathrm{~g} / \mathrm{mol}[\mathrm{M}+\mathrm{Na}]^{+}$. Berdasarkan data spektrofotometer UV-Vis, FTIR dan LC-MS diketahui bahwa isolat $A_{1.1}$ dan isolat $A_{2.1}$ merupakan senyawa alkaloid tropan yang mengikat gugus $\alpha, \beta$ asam tak jenuh dan mempunyai gugus fungsi $\mathrm{O}-\mathrm{H}, \mathrm{C}=\mathrm{O}, \mathrm{C}-\mathrm{O}, \mathrm{C}-\mathrm{N}, \mathrm{CH}_{2}$ dan $\mathrm{CH}_{3}$. Berat molekul dari kedua isolat adalah 337,34 $\mathrm{g} / \mathrm{mol}$ dan 337,33 g/mol. Analisis menggunakan spektrometer LC-MS kedua isolat sitampilkan pada gambar 5 .
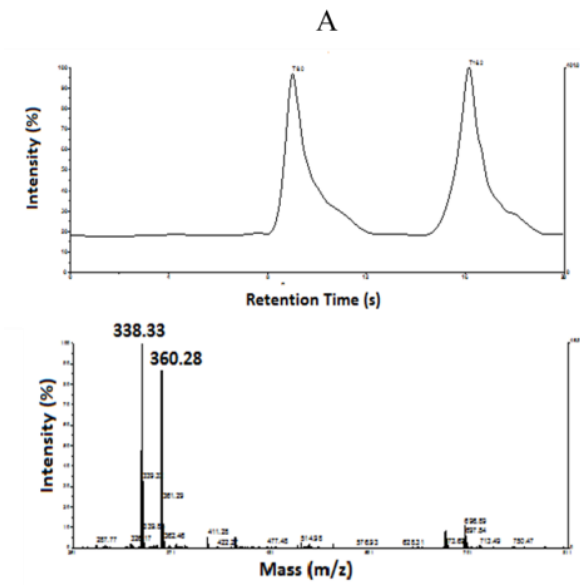

B
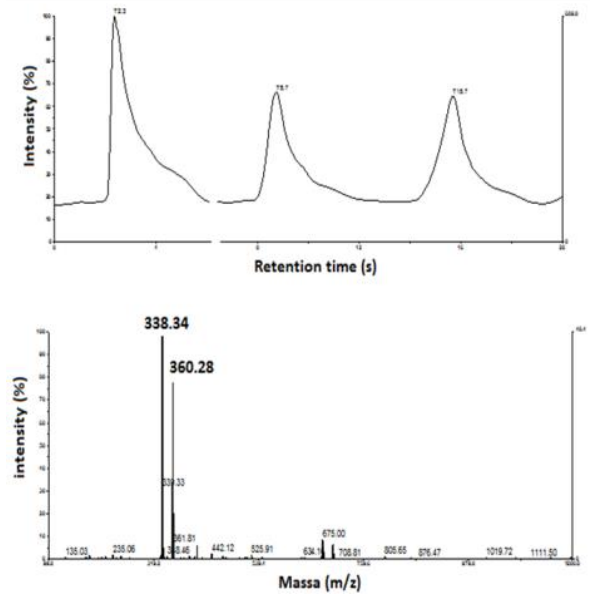

Gambar 5. Kromatogram dan spektogram LC-MS isolat $\mathrm{A}_{1.1}(\mathrm{~A})$ dan isolat $\mathrm{A}_{2.1}(\mathrm{~B})$

Kerangka dasar dari alkaloid tropan ditunjukkan pada gambar 6 .

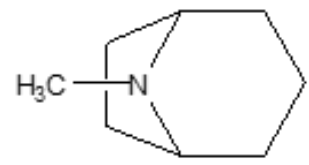

Gambar 6. Gambar kerangka dasar senyawa alkaloid tropane

Uji sitotoksik terhadap isolat alkaloid total dilakukan dengan metode Brine Shrimp Lethlity Test (BSLT). Uji tersebut menggunakan larva Artemia salina Leach yang berumur 2 hari. Pengamatan pengujian adalah 24 jam setelah perlakuan. JumLah larva Artemia salina Leach yang mati dihitung dan dicatat untuk masing-masing konsentrasi larutan uji Berdasarkan hasil pengolahan data dengan Probit Analysis diperoleh harga $\mathrm{LC}_{50}$ dari alkaloid total yaitu sebesar 132,590 ppm. Menurut Moshi $d k k$. [12] harga $30 \mathrm{ppm}<\mathrm{LC}_{50} \leq 100$ ppm bersifat sedikit toksik, harga $\mathrm{LC}_{50}>100 \mathrm{ppm}$ bersifat tidak toksik. Oleh karena itu, dapat disimpulkan bahwa isolat alkaloid total bersifat tidak toksik.

\section{Kesimpulan}

Senyawa alkaloid dapat diisolasi dari daun ketapang berbentuk serbuk berwarna putih. Jenis alkaloid yang diperoleh adalah alkaloid tropan yang mengikat gugus 
$\alpha, \beta$ asam tak jenuh, mempunyai gugus fungsi $\mathrm{O}-\mathrm{H}, \mathrm{C}=\mathrm{O}$, $\mathrm{C}-\mathrm{O}, \mathrm{C}-\mathrm{N}, \mathrm{CH}_{2}$ dan $\mathrm{CH}_{3}$ serta berat molekul 337,34 g/mol. Sedangkan isomernya mempunyai gugus fungsi $\mathrm{O}-\mathrm{H}$, $\mathrm{C}=\mathrm{O}, \mathrm{C}-\mathrm{O}, \mathrm{C}-\mathrm{N}, \mathrm{CH}_{2}$ dan $\mathrm{CH}_{3}$ serta berat molekul 337,33 $\mathrm{g} / \mathrm{mol}$. Hasil uji sitotoksik terhadap alkaloid total daun ketapang mempunyai harga $\mathrm{LC}_{50}$ sebesar $132,590 \mathrm{ppm}$ yang berarti isolat alkaloid total bersifat tidak toksik.

\section{Daftar Pustaka}

[1] Gilles Pauly, Cosmetic, dermatological and pharmaceutical use of an extract of Terminalia catappa, in, Google Patents, 2001.

[2] DS Mohale, AP Dewani, AV Chandewar, CD Khadse, AS Tripathi, SS Agrawal, Brief Review on Medicinal Potential of Terminalia catappa, Journal of Herbal Medicine and Toxicology, 3, 1, (2009) 7-11

[3] Afni Restasari, Dewi Kusrini, Enny Fachriyah, Isolasi dan identifikasi Fraksi Teraktif dari Ekstrak Kloroform Daun Ketapang (Terminalia catappa Linn), Departemen Kimia, Universitas Diponegoro, Semarang

[4] Dwi Sri Rahayu, Dewi Kusrini, Enny Fachriyah, Penentuan Aktivitas Antioksidan dari Ekstrak Etanol Daun Ketapang (Terminalia catappa L) dengan Metode 1, 1-Difenil-2-Pikrilhidrazil (DPPH), Departemen Kimia, Universitas Diponegoro, Semarang

[5] Anindya Dwi Rosita, Isolasi Dan Identifikasi Komponen-Komponen Senyawa Hidrokarbon Dalam Minyak Atsiri Daun Ketapang (Terminalia catappa L), Departemen Kimia, Universitas Diponegoro, Semarang

[6] Ibok Oduro, C Larbie, TNE Amoako, AF AntwiBoasiako, Proximate composition and basic phytochemical assessment of two common varieties of Terminalia catappa (Indian Almond), Journal of Science and Technology (Ghana), 29, 2, (2009) http://dx.doi.org/10.4314/just.v29i2.46217

[7] Anupam Ghosh, Bidus Kanti Das, Arup Roy, Biplab Mandal, Goutam Chandra, Antibacterial activity of some medicinal plant extracts, Journal of natural medicines, $\quad 62, \quad 2, \quad$ (2008) 259-262 http://dx.doi.org/10.1007/s11418-007-0216-x

[8] Norman R. Farnsworth, Biological and phytochemical screening of plants, Journal of Pharmaceutical Sciences, 55, 3, (1966) 225-276 http://dx.doi.org/10.1002/jps.2600550302

[9] B. N. Meyer, N. R. Ferrigni, J. E. Putnam, L. B. Jacobsen, D. E. Nichols, J. L. McLaughlin, Brine Shrimp: A Convenient General Bioassay for Active Plant Constituents, Planta Med, 45, 05, (1982) 31-34 http://dx.doi.org/10.1055/s-2007-971236

[10] RJ Fessenden, JS Fessenden, Kimia Organik, diterjemahkan oleh Pudjaatmaka, AH, jilid, 1, (1994) 209-210

[11] Munir Humam, Thomas Kehrli, Damien Jeannerat, Orlando Muñoz, Kurt Hostettmann, Philippe Christen, Schizanthines N, O, and P, Tropane Alkaloids From The Aerial Parts of Schizanthus Tricolor, Journal of natural products, 74, 1, (2010) 5053

[12] MJ Moshi, E Innocent, JJ Magadula, DF Otieno, A Weisheit, PK Mbabazi, RSO Nondo, Brine shrimp toxicity of some plants used as traditional medicines in Kagera region, north western Tanzania, Tanzania journal of health research, 12, 1, (2010) 63-67 http://dx.doi.org/10.4314/thrb.v12i1.56287 